Article

\title{
Design and Implementation of a Low-Cost Real-Time Control Platform for Power Electronics Applications
}

\author{
José Aravena ${ }^{1}$, Dante Carrasco ${ }^{1}$, Matias Diaz ${ }^{1, *}$ (৫) , Matias Uriarte ${ }^{1}$, Felix Rojas ${ }^{1}$, \\ Roberto Cardenas $^{2}$ and Juan Carlos Travieso ${ }^{1}$ \\ 1 Electrical Engineering Department, University of Santiago of Chile, Avenida Ecuador 3519, \\ Santiago 9170124, Chile; jose.aravenac@usach.cl (J.A.); dante.carrasco@usach.cl (D.C.); \\ matias.uriarte@usach.cl (M.U.); felix.rojas@usach.cl (F.R.); juancarlos.travieso@usach.cl (J.C.T.) \\ 2 Electrical Engineering Department, University of Chile, Avenida Tupper 2007, Santiago 8370451, Chile; \\ rcd@ieee.org \\ * Correspondence: matias.diazd@usach.cl
}

Received: 5 February 2020; Accepted: 17 March 2020; Published: 24 March 2020

check for

\begin{abstract}
In recent years, different off-the-shelf solutions for the rapid control prototyping of power electronics converters have been commercialised. The main benefits of those systems are based on a fast and easy-to-use environment due to high-level programming. However, most of those systems are very expensive and are closed software and hardware solutions. In this context, this paper presents the design and implementation of a control platform targeting at the segment in between expensive off-the-shelf control platforms and low-cost controllers. The control platform is based on the Launchpad TMS320F28379D from Texas Instruments, and it is equipped with an expansion board that provide analogue-to-digital measurements, switching signals and hardware protections. The performance of the control platform is experimentally tested on a $20 \mathrm{kVA}$ power converter.
\end{abstract}

Keywords: control platforms; power electronics converter; control

\section{Introduction}

Some of the principal challenges in power electronics research are the fast development of new topologies, such as modular multilevel converters and matrix converters, and the requirement of new control strategies, such as non-linear control and model predictive control [1]. Frequently, new topologies have more components, and new control strategies require more powerful computational capabilities [2]. Accordingly, the controller is a critical element of every power electronics converter that should provide real-time control of the operation of the converter [3].

In industrial applications, the controller, usually referred to as Real-Time Control Platform (RTCP), is designed to be as cheap as possible and intended for the specific application with it will be used. On the other hand, sophisticated control platforms are used in research and development to provide Rapid-Control-Prototyping (RCP). RCP enables a more straightforward identification of design errors in the development process, diminishing delays, and improving the overall product quality [4]. For research and development, technology demonstrations can be performed in earlier project stages, without the requirement for complex coding and integration [5].

In power electronics, RCP is widely used to test and iterate control strategies in a developing stage, and it is also used to test control techniques and topologies. Based on these requirements, different controllers have been developed and commercialised on the market as off-the-shelf products. Among the leading market players, dSpace controllers represent a well-known example [6], as they offer a wide range of different solutions for research in power electronics. Several research works have reported experimental implementations using DSpace devices. OPAL-RT is another popularly used 
solution for Real-Time (RT) simulation, RCP, and Hardware-in-the-Loop (HIL) control and testing of power converters $[7,8]$. The RT-Box controller is designed for RCP and HIL tests, and it is compatible with PLECS software [9]. Additionally, Imperix controller offers similar functionalities than the RT-Box in their controller referred to as Boombox RT [10]. Another commercial solution is the PED-Board, a power electronic controller with several interface boards [11]. Finally, it is important to mention HIL producers as Typhon [12] and RTDS [13].

Table 1 presents the main characteristics of the off-of-the-shell controllers already available on the market. Most of them can handle up to 32 Digital Inputs (DI) and Digital Outputs (DO), and 32 Analogue Input (AI) and Analogue Outputs (AO). Additionally, besides the cost of the controller, licensed software must be acquired. Regardless of the multiple advantages offered by the products above-mentioned, those systems have a high price limiting its use for applications where a high number of RCP platforms is required. Additionally, most of those systems are closed software and hardware solutions, restricting the flexibility and adjustment for particular purposes.

Table 1. Benchmarking of-the-shell commercial RTCP.

\begin{tabular}{lccccccc}
\hline $\begin{array}{l}\text { Model/ } \\
\text { Brand }\end{array}$ & AI & DO & DI & AO & Hardware & $\begin{array}{c}\text { Approximately } \\
\text { Price [USD] }\end{array}$ & Software \\
\cline { 2 - 7 } $\begin{array}{l}\text { OP4510/ } \\
\text { OPAL-RT }\end{array}$ & 16 & 32 & 32 & 16 & $\begin{array}{c}\text { CPU Intel Xeon 4 cores, } \\
\text { FPGA Kintex-7 }\end{array}$ & 25.000 & $\begin{array}{l}\text { Licensed } \\
\text { software }\end{array}$ \\
\hline $\begin{array}{l}\text { RT-BOX/ } \\
\text { Plexim }\end{array}$ & 16 & 32 & 32 & 16 & $\begin{array}{c}\text { Xilinx Zynq Z-7030 } \\
\text { (CPU 2 cores+FPGA) }\end{array}$ & 9.800 & $\begin{array}{l}\text { Licensed } \\
\text { software }\end{array}$ \\
\hline $\begin{array}{l}\text { MicroLabBox/ } \\
\text { dSPACE }\end{array}$ & 8 & $\begin{array}{c}48 \\
\text { shared }\end{array}$ & $\begin{array}{c}48 \\
\text { shared }\end{array}$ & 16 & $\begin{array}{c}\text { PowerPC DualCore 2 GHz } \\
\text { Kintex-7 FPGA }\end{array}$ & 15.000 & $\begin{array}{l}\text { Licensed } \\
\text { software }\end{array}$ \\
\hline $\begin{array}{l}\text { BoomBox/ } \\
\text { Imperix }\end{array}$ & 16 & 16 & - & 4 & $\begin{array}{c}\text { SOC Zynq XC7Z030-3FBG676E } \\
\text { FPGA ProASIC3 }\end{array}$ & 13.000 & $\begin{array}{l}\text { Licensed } \\
\text { software }\end{array}$ \\
\hline $\begin{array}{l}\text { V3/ } \\
\text { PED-Board }\end{array}$ & 24 & 30 & 46 & 4 & $\begin{array}{c}\text { SoM sbRIO-9651 } \\
\text { FPGA Zynq-7020 }\end{array}$ & 1.500 & $\begin{array}{l}\text { Licensed } \\
\text { software }\end{array}$ \\
\hline $\begin{array}{l}\text { HIL402/ } \\
\text { Typhoon }\end{array}$ & 16 & 32 & 32 & 16 & $\begin{array}{c}\text { SOC Zynq XC7Z030 } \\
\text { Licensed } \\
\text { software }\end{array}$ \\
\hline
\end{tabular}

To handle this problem, multiple research groups have developed custom RTCPs based on low-cost Digital-Signal Processors (DSPs) and Field-Programmable Gate Array (FPGA).

Tailored RCP platforms have been developed. For instance, a novel control platform, referred to as uCube, has been developed by the University of Nottingham and it is aimed at low-cost RCP market [14]. The uCube is based on the Microzed evaluation board equipped with the Xilinx Zynq-7000 System on a Chip (SoC). The uCube has expansion boards that can handle 24 optical fibre channels, 16 Analog Digital (AD) converters and encoder reading. In [15], a new real-time computing platform based on a high-performance FPGA SoC is presented. The platform is suitable for the implementation of complex control algorithms, and it can handle complex topologies with a high number of I/O. Compared to many commercial platforms, it offers the advantages of a fully adjustable logic system and a customised amount of analogue inputs and digital I/O.

Tailored HIL implementations can also be found in the literature. An experimental platform for microgrid HIL analyses is presented in [16]. In this case, the physical system is emulated using an OPAL-RT emulator and the control layer is implemented using Raspberry-Pi. Similarly, an RTDS real-time emulator is implemented for power HIL experiments [17]. Additionally, the development of a real-time virtual test bed for HIL is presented in [18]. The system uses Linux and open software to reduce the total cost. The same platform is used to test HIL of a boost converter and a full-bridge in power electronics applications [19]. Furthermore, a HIL implementation using a DSP LaunchPad C2000 Delfino F28377S is presented for microgrids applications in [20]. Three different converters are modelled in this study to validate the capabilities of the proposed DSP based HIL platform. 
The main drawback of low-cost platforms for HIL emulation and RCP is that the time of development is long, and expertise in DSP and FPGA based development is needed to work with them. Besides, it is challenging to carry out a precise comparison of them, because most of the low-cost platforms are not commercially available and they are case a case implemented by research groups, tailored to a particular application. However, using the comparison reported in [20], it is concluded that the control systems implemented utilising some DSP platforms, can achieve time steps as low as $860 \mathrm{~ns}$, higher than that achievable with the (relatively high cost) Typhoon system $(\approx 560 \mathrm{~ns})$ but still good enough to represent IGBTs in some typical application, for instance, microgrids, where the power converter switching frequency is about $10 \mathrm{kHz}$. As discussed in [8], the implementations based on FPGAs are also relatively low-cost alternatives for HIL and RTCP, achieving applications with low time steps. However, the lack of high-level software programming tools could be a significant disadvantage in this case (see [8]).

In this context, this paper presents the design and implementation of a low-cost and effortless RTCP for RCP of power electronics applications. The proposed RTCP is based on the Delfino TMS320F28379D microcontroller from Texas Instruments. Additionally, due to the complementary resources of the Delfino TMS320F28379D microcontroller, the RTCP can be programmed using either $\mathrm{C} / \mathrm{C}++$ code or Matlab Simulink. The principal contributions of this paper can be summarised as follows:

- A benchmark on the main off-the-shelf controllers for HIL and RCP applications is presented. To the best of the authors' knowledge, the principal commercial alternatives have been included and compared in terms of the number of input-output capabilities, price and requirement of licensed software.

- An expansion board is designed to expand the capabilities of the Delfino TMS320F28379D microcontroller. This expansion board is equipped with analogue-to-digital measurements, optical fibre Pulse Wide Modulation (PWM), and hardware protections.

- The effectiveness of the proposed RTCP for power electronics applications is validated by experiments conducted with a $20 \mathrm{kVA}$ power converter.

The rest of the paper is organised as follows. A benchmark on the main off-the-shelf controller characteristics is presented in Section 2. The proposed RTCP is detailed, and its main functionalities are explained in Section 3. Next, an example application and its implementation on the RTCP are presented. Later, the performance of the control platform is experimentally tested on a $20 \mathrm{kVA}$ power converter. Lastly, conclusions are provided.

\section{Design of the RTCP}

The proposed RTCP is equipped with the launchpad LAUNCHXL-F28379D of Texas Instrument. This launchpad is based on a 32-bit floating-point Delfino microcontrollers, model TMS320F28379D, which is designed for advanced closed-loop control applications. The Delfino launchpad LAUNCHXLF28379D is shown in Figure 1a and its key features are described below:

- Dual-Core architecture with two TMS320C28x 32-Bit CPUs;

- $200 \mathrm{MHz}$ Clock;

- 1 MB Memory flash;

- Analogue and control peripherals include Digital Analog Converter (DAC), PWM, Enhanced Capture (eCAP), Enhanced Quadrature Encoder Pulse (eQEP), and other peripherals;

- USB, CAN, I2C and SPI interface;

- 24 Analogue-to-Digital (AD) signal channels with 12 or 16 bit resolution;

- 24 PWM channels with 16 bit resolution and dead time support. 
The proposed RTCP expands the launchpad capabilities through the implementation of an expansion board, as shown in Figure 1b. The RTCP provides optical fibre interfaces that can be used to transmit PWM signals, it performs signal conditioning to measure analogue signals, and it provides hardware protections. All the protections are cascaded to interrupt the operation of the converter if over-voltages or over-currents arise. The expansion board is presented in Figure 2. It is a four-layer PCB (Printed Circuit Board) measuring $179 \times 156 \mathrm{~mm}$. Its main components are drivers for an optical fibre interface, operational amplifiers for analogue-digital conversion, and comparators and logic gates for hardware protection. The total RTCP cost is approximately USD 400, as presented in Table 2, and it considers the cost of the Delfino Launchpad, plus the expansion board assembly and electronic components.

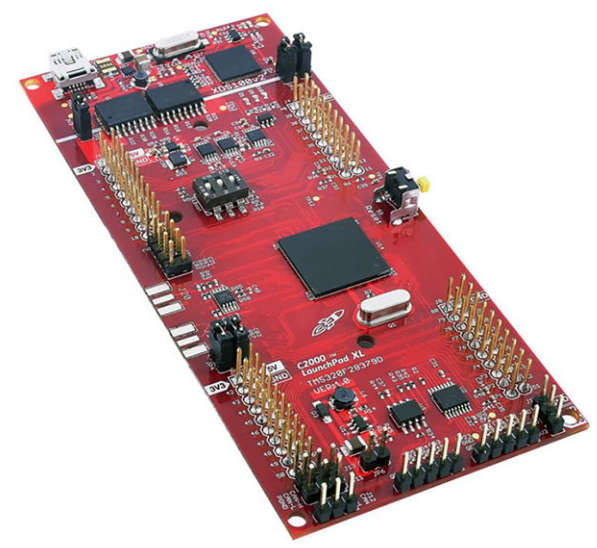

(a)

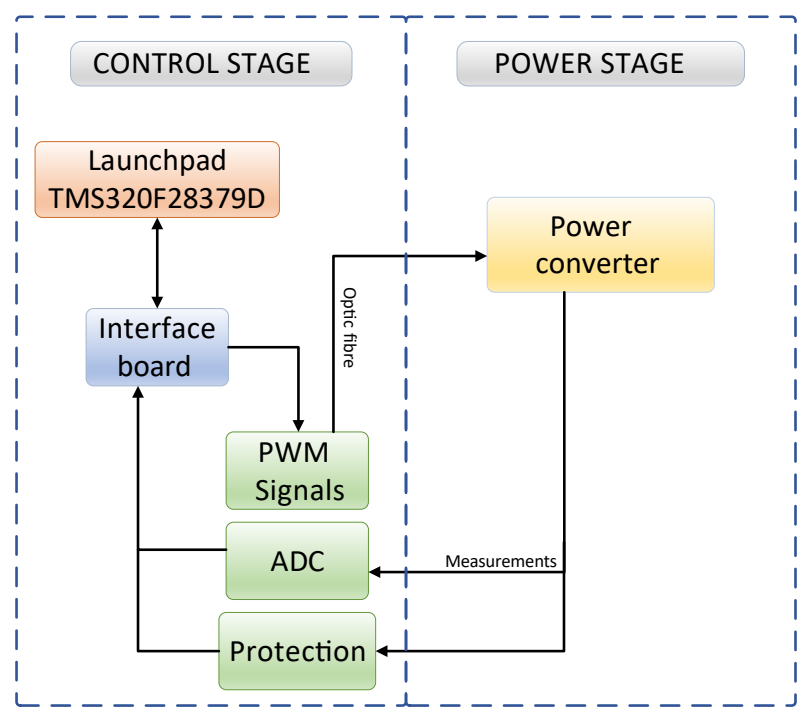

(b)

Figure 1. (a) Launchpad TMS320F28379D. (b) Overview of the proposed RTCP.

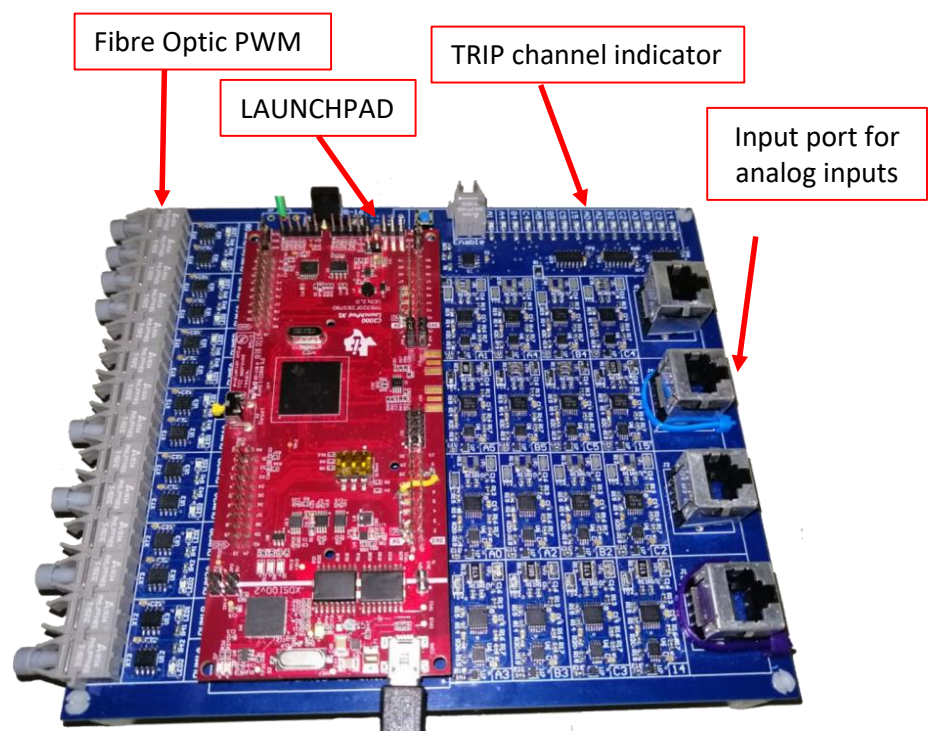

Figure 2. Soldered Printed Circuit Board. 
The principal features of the proposed RTCP are listed below and they are detailed in the next subsections.

- 14 PWM channels with optical transmitters;

- 16 AD channels with 12 bit resolution;

- 16 hardware protections implemented with digital potentiometers;

- Dedicated connector to access USB, CAN, I2C and SPI communication in.

Table 2. Main components and cost of the RTCP.

\begin{tabular}{lccc}
\hline \multicolumn{4}{c}{ RTCP Cost } \\
\hline Item & Quantity & Cost per Unit (USD) & Total Cost (USD) \\
\hline Bare PCB & 1 & 5 & 5 \\
Delfino board & 1 & 35 & 35 \\
Fiber optic transmitters & 14 & 10 & 140 \\
IC fiber optic drivers & 14 & 1 & 14 \\
IC OP-AMP & 16 & 5 & 80 \\
IC Comparators & 16 & 4 & 64 \\
IC Logic gates & 20 & 0.2 & 10 \\
Passive components & 1 & 20 & 20 \\
Connectors & 1 & 30 & 30 \\
\hline
\end{tabular}

\subsection{Electrical/Optical Stage for PWM Signals}

The PWM signals generated by the Launchpad are sent to the power stage by optical fibre interface. For this purpose, the expansion board considers drivers for each PWM signal. The optical fibre interface circuit is shown in Figure 3. Each driver is composed of a low-input impedance buffer connected to the gate of a MOSFET that switches on and off to activate the optical fibre. The microcontroller is capable of generating PWM signals up to $100 \mathrm{MHz}$. Notice when increasing the PWM frequency reduces its duty cycle resolution due to the $200 \mathrm{MHz}$ system clock of the microcontroller.

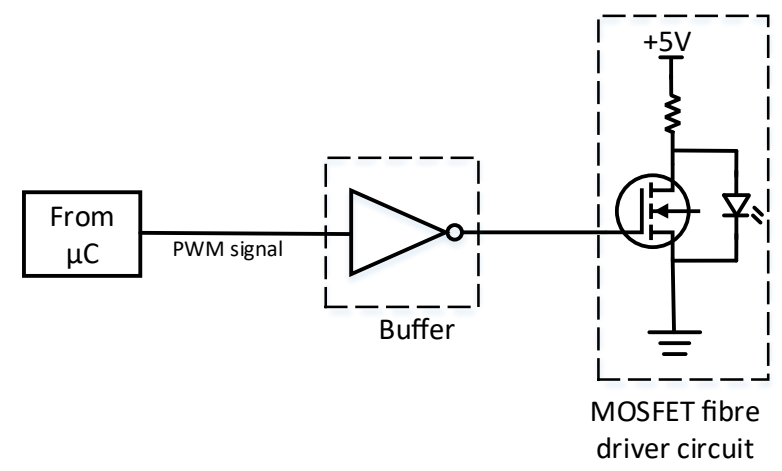

Figure 3. Optical fibre driver circuit.

Using the optical fibre interface to send the PWM signals has advantages such as noise immunity and electrical isolation between the control and the power stage [21,22]. Is important to notice that the TMS320F28379D chip is capable of generating 24 PWM signals. However, the Launchpad board is available with only 14 of them. For that reason, 14 optic fibres were considered in the final design of the board.

\subsection{Adaptation Stage for Analog Input Signals}

The measurement of analogue signals requires an adaptation stage to match AD capabilities. Therefore, processing of the AD signals is performed scaling and applying offset to the original signals. The range of the final signal is defined between 0 and 3 volts not to saturate the AD converter. 
Figure 4 presents the electrical circuit used in the AD conversion. The TMS320F28379D chip consists of 4 independent Analog Digital Converter (ADC) channels. Each of them is capable of measuring six multiplexed signals allowing the microcontroller to read a total of signals. However, the Launchpad board provides 16 of them. For that reason, 16 analogue measurements were considered in the final design of the board.

\subsection{Hardware Protections}

A protection circuit based on digital comparators and potentiometers has been implemented on the interface board. The main goal of these circuits is to protect the power converter from over-voltage or over-current events.

The comparators receive a reference signal generated by a voltage divider. The digital potentiometers can be regulated to adjust this reference signal. Then, the reference is compared to the analogue input signal, as shown in Figure 4. If the defined thresholds are exceeded, the comparator generates a warning signal and deactivates the switching devices. LEDs located on the side of the board indicate which channel was tripped. To modify the values of the digital potentiometer, the new data must be sent from Matlab Simulink to the board through I2c communication.

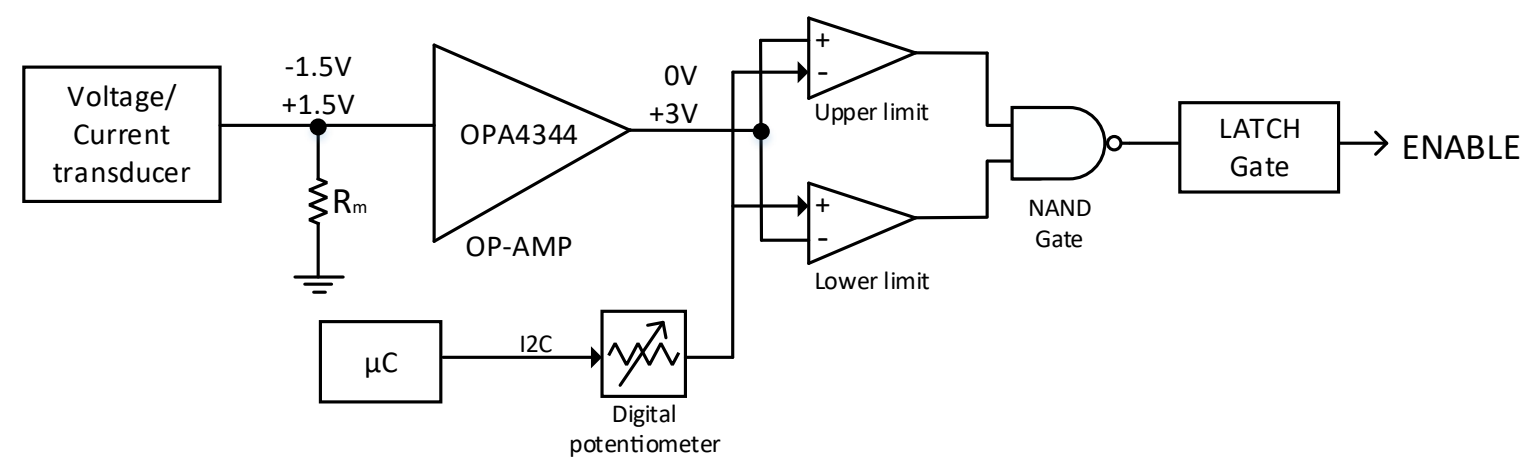

Figure 4. Electrical protection based on comparators and logic gates.

\subsection{ADC Configuration}

In power electronic applications, usually, the RTCP execute control algorithms in a closed-loop manner. This means that the RTCP must first read the AD signals, i.e., voltages and currents, and depending on these values, to execute the algorithm. Then, the references for the PWM modulation and the switching signals are updated. Hence, it is imperative to know the controller computing capacity, as well as the technical characteristics of the AD and PWM interface, to ensure proper execution of the control algorithms.

The power converters incorporate a voltage and current feedback requiring analogue inputs. For this requirement, the controllers typically include embedded AD converters to convert the analogue voltages and currents into digital variables to be interpreted by the microcontroller.

The TMS320F28379D microcontroller incorporates 12-bit or 16-bit AD channels with 1.1 or 3.5 Mega Samples per Second (MPS) capability. The AD conversion can be set in a single-ended or differential configuration. Internally, the microcontroller has four independent AD channels labelled A, $\mathrm{B}, \mathrm{C}$ and $\mathrm{D}$, which allows reading four signals simultaneously. Using multiplexing, the microcontroller can read up to 24 analogue signals.

The ADC configuration is presented in Figure 5. Each analogue signal is read by one of the blocks whose execution logic is defined by Start-Of-Conversions (SOC). The SOC defines the source that triggers the $\mathrm{AD}$ reading, the channel to be converted and the acquisition interval.

Subsequently, an acquisition interval is defined. The acquisition interval is the amount of time needed by the sampling capacitor is enabled to charge. This mechanism allows retaining the data for 
a time specified by the user (S/H Sample and Hold). Typical acquisition values range from $10 \mathrm{~ns}$ to $500 \mathrm{~ns}$.

Finally, the AD block processes the data and save it in a register. This register can be accessed by the microcontroller to execute the control algorithm.

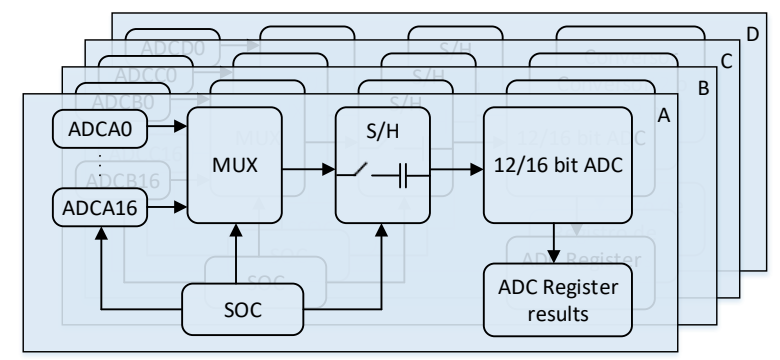

Figure 5. ADC Operation Diagram.

\subsection{PWM Configuration}

The PWM is one of the essential peripherals of a microcontroller since it provides the necessary signals to command the power devices (typically MOSFET and IGBTs) using a gate driver. This driver must be able to provide galvanic isolation between the control and power stages and generate the appropriate voltage to turn on-off the devices.

One of the requirements of the PWM peripheral is that it must generate signals with precise pulse width and high resolution with minimal CPU usage. For this purpose, the TMS320F28379D chip incorporates a peripheral capable of generating the PWM signals. This peripheral is easy to program, highly flexible and only requires a message from the CPU to update its new value.

The TMS320F28379D chip contains 12 independent PWM blocks of 16 bits each. Counters and comparators, define the frequency and duty cycle of the PWM, respectively.

Figure 6a shows the operation of the PWM block. Each PWM block consists of two submodules, namely submodules A and B, that provide a total of 24 PWM signals. The submodules can be configured as complementary signals, meaning that $\mathrm{A}$ is the boolean negative of Besides, it is also possible to set dead times between them, which is a useful function to manipulate two IGBTs of a single leg. The communication between the CPU and the PWM block is done through a common bus where information is shared. This information can be continuously updated in real-time as necessary, either to modify the pulse width of the PWM, its period or another parameter.

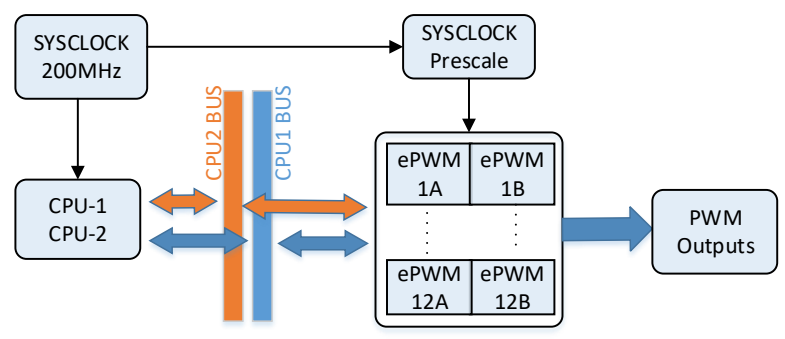

(a)

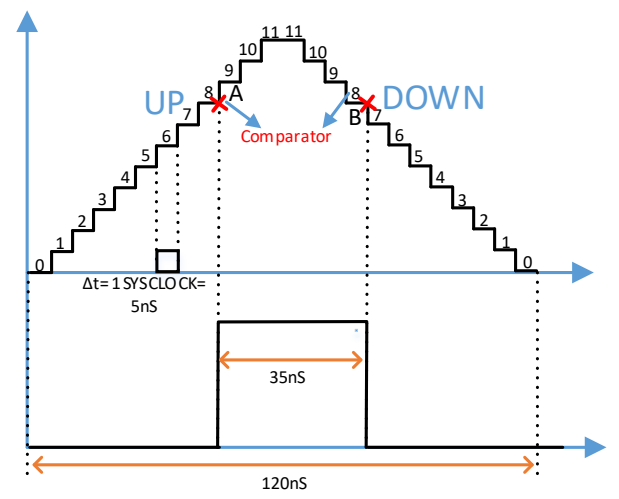

(b)

Figure 6. (a) PWM block operation diagram. (b) PWM signal generation with Up-Down type counter. 
For a basic configuration of the PWM blocks, the input parameters are to the counter and the comparator. The counter is an integer between 0 and 65,535 that represents the counts that will be made in clock cycles. The crystal frequency determines the clock cycles. This crystal is $200 \mathrm{MHz}$ which means that each account is equivalent to a period of $5 \mathrm{~ns}$.

The behaviour of the counter can be set as Up-Down, Up and Down. In the Up-Down mode, the counter starts counting from zero until it reaches the defined setpoint. Once it reaches the value, it returns with a descending counter until it reaches zero and then repeats the process indefinitely. On the one hand, the Up mode starts with an ascending count from zero until reaching the defined number repeating the process. On the other hand, the Down mode counter behaves like the Up counter but in the opposite way, starting with the maximum count and then descending until it reaches zero.

The comparator is an integer value between zero and the maximum count value. This value can be set by the user or be continuously refreshed as needed. When the counter reaches the comparison value, the user can trigger different events pulling the PWM signal in high or low. The example in Figure $6 \mathrm{~b}$ shows an Up-Down counter of 11 counts and two points of comparison. The signal is set to low when the counter is equal to zero, set to high when it reaches comparator $\mathrm{A}$ and then set to low when it reaches comparator B.

The signal generated in Figure $6 \mathrm{~b}$ is a high-frequency signal since a small number of clock cycles were used for illustrative purposes. For lower order frequencies, a higher counter can be set, or the SYSCLOCK (oscillator frequency equal to $200 \mathrm{MHz}$ ) can be scaled to half its frequency, decreasing the PWM frequency by half.

\section{Power Electronic Application to Test the RTCP}

The performance of the proposed RTCP for power electronics RCP applications is validated using the scheme presented in Figure 7a. The proposed RTCP is used as RCP to control a generic power converter. In this case, an AC-DC back-to-back converter is utilised as an example. The power converter is used to transfer power from an AC grid to a DC Resistive-Inductive (RL) load. The AC-DC back-to-back converter is composed of a controlled rectifier equipped with IGBTs, and a DC-DC converter based on a full-bridge, as shown in Figure $7 \mathrm{~b}$.

The RTCP has a direct interface to a computer, and it can be programmed in $\mathrm{C} / \mathrm{C}++$ using Code Composer Studio. Additionally, it has MathWorks Embedded Target Support for easy programming and debugging in Simulink. The launchpad LAUNCHXL-F28379D has a predefined blocks library that can be accessed from Texas Instrument website [23]. Additional self-designed control blocks can also be used and mixed with the predefined block from Texas Instrument library.

To control the AC-DC back-to-back converter, the control strategy displayed in Figure 8 is programmed in the RTCP. The converter is regulated to operate as an interlinking AC-DC converter to achieve AC-DC power transference [24,25]. The controlled rectifier is regulated using a dq control strategy and a Proportional-Integral (PI) controllers as proposed in [26,27]. Additionally, the full-bridge is operated in grid feeding mode, and the DC current is regulated using a PI controller. Both control strategies are linked through the feed-forward shown in Figure 8. The parameters used in the PI controllers are shown in Table 3.

Table 3. Design parameters for PI controllers.

\begin{tabular}{lcc}
\hline Control Loop & $\omega_{n}$ & $\zeta$ \\
\hline Id Current loop & 100 & 0.707 \\
Iq Current loop & 100 & 0.707 \\
Vd Voltage Nested loop & 12 & 0.9 \\
Idc Current loop & 20 & 0.9 \\
\hline
\end{tabular}




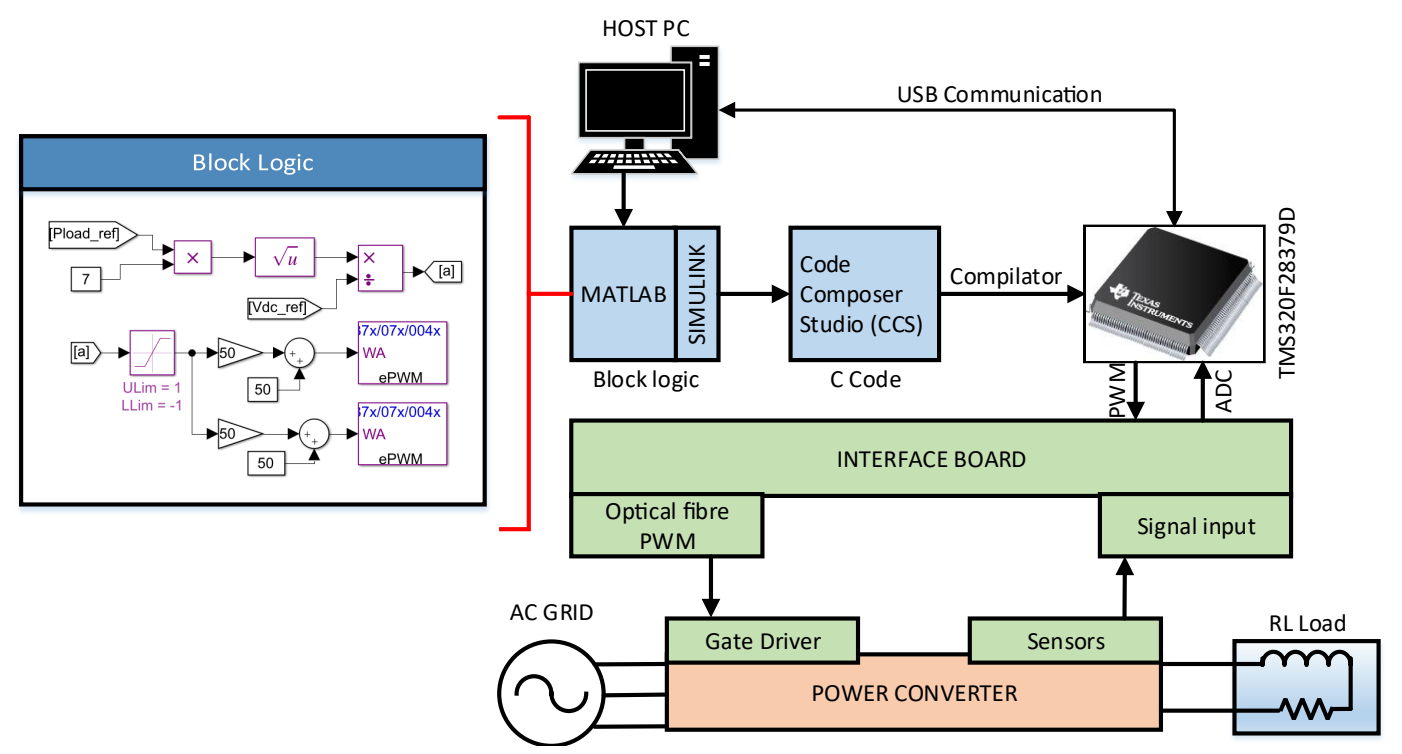

(a)

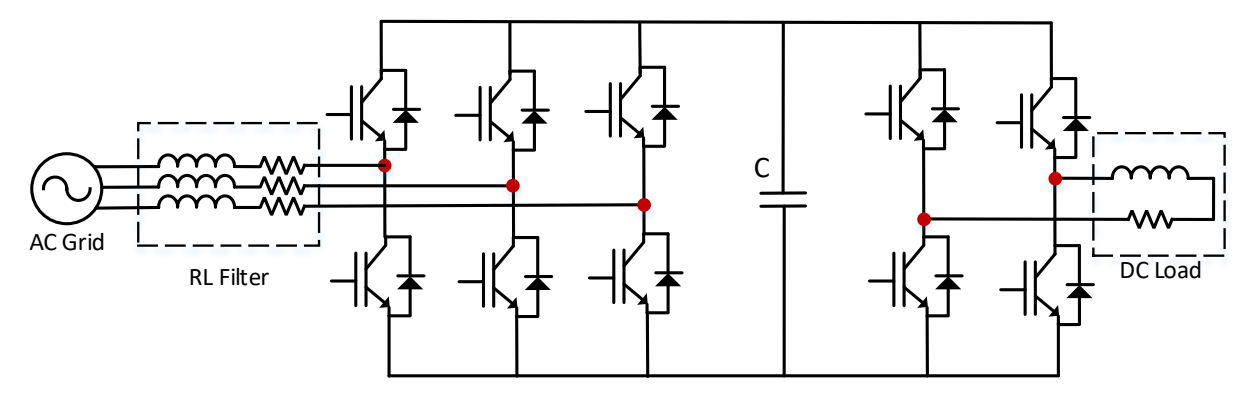

(b)

Figure 7. (a) Overview of the experimental setup. (b) AC-DC back-to-back converter topology.

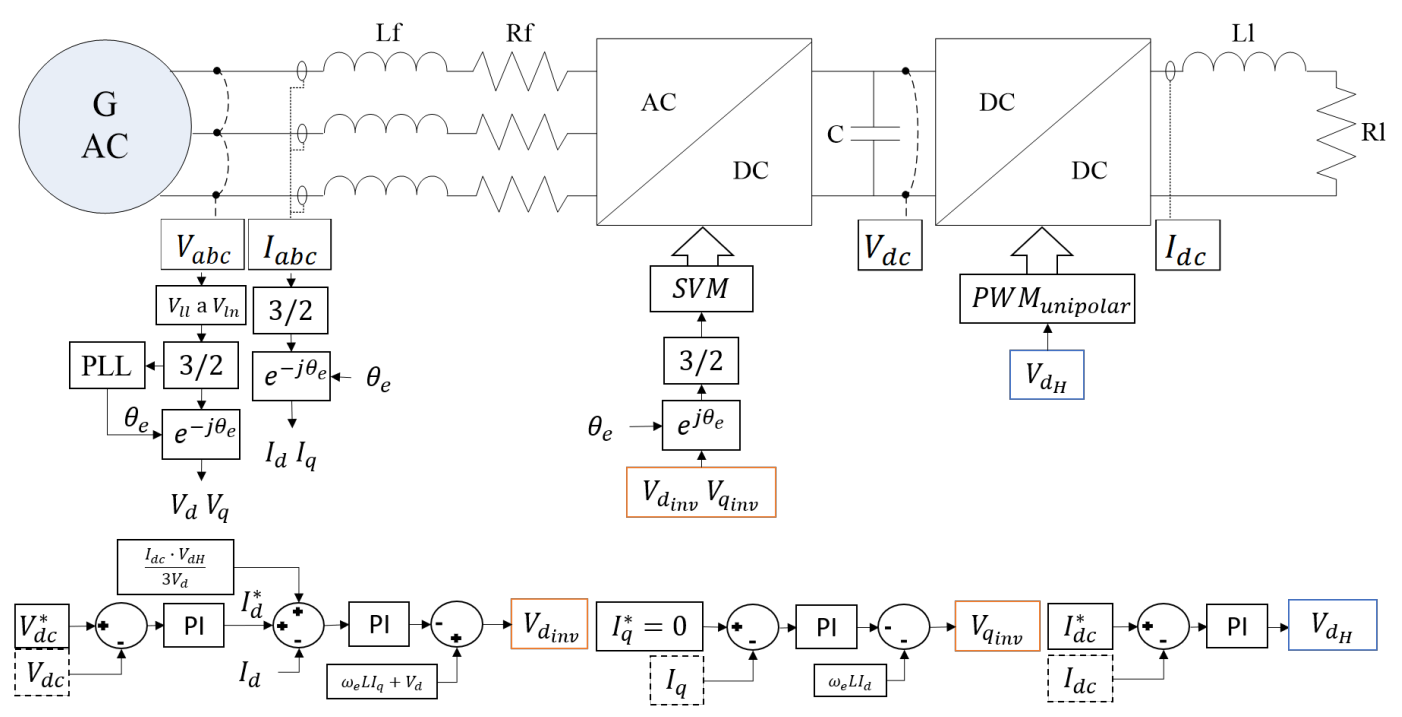

Figure 8. Proposed control algorithm.

The implemented experimental system is shown in Figure 9 where the power converter, control platform and RL load lays inside. A metal box covers the control platform for noise immunity. A Variable AC source is used to work with variable voltage in the AC side. The main parameters of the power converter are specified in Table 4 . The AC-DC controlled rectifier is equipped with Infineon IGBTs, model FF75R12R74, with a nominal current of $75 \mathrm{~A}$ and an emitting collector voltage of $1200 \mathrm{~V}$. 
The DC-DC full-bridge is equipped with Infineon IGBTs model FF300R12KT4, with a nominal capacity of $300 \mathrm{~A}$ and $1200 \mathrm{~V}$. Both devices have a modular packaging that contains two IGBTs that form a converter leg. Finally, it is worth to mention that the DC-Link has a capacity of $2 \mathrm{mF}$ and supports $800 \mathrm{~V}$.

Table 4. Power stage main parameters.

\begin{tabular}{lcc}
\hline Parameter & Value & Unit \\
\hline Rated power & 20 & $\mathrm{kVA}$ \\
AC Input voltage & 380 & $\mathrm{~V}$ \\
Maximum DC current & 150 & $\mathrm{~A}$ \\
Maximum DC voltage & 750 & $\mathrm{~V}$ \\
Switching frequency & 5 & $\mathrm{kHz}$ \\
C_dc-link & 2 & $\mathrm{mF}$ \\
$\mathrm{Rf}$ & 0.03 & $\Omega$ \\
Lf & 5 & $\mathrm{mH}$ \\
Rl & 2 & $\Omega$ \\
Ll & 4 & $\mathrm{mH}$ \\
Collector-emitter Voltage_IGBTs & 1200 & $\mathrm{~V}$ \\
Continuous DC collector current_FF300R12KT4 & 300 & $\mathrm{~A}$ \\
Continuous DC collector current_FF75R12R74 & 75 & $\mathrm{~A}$ \\
\hline
\end{tabular}

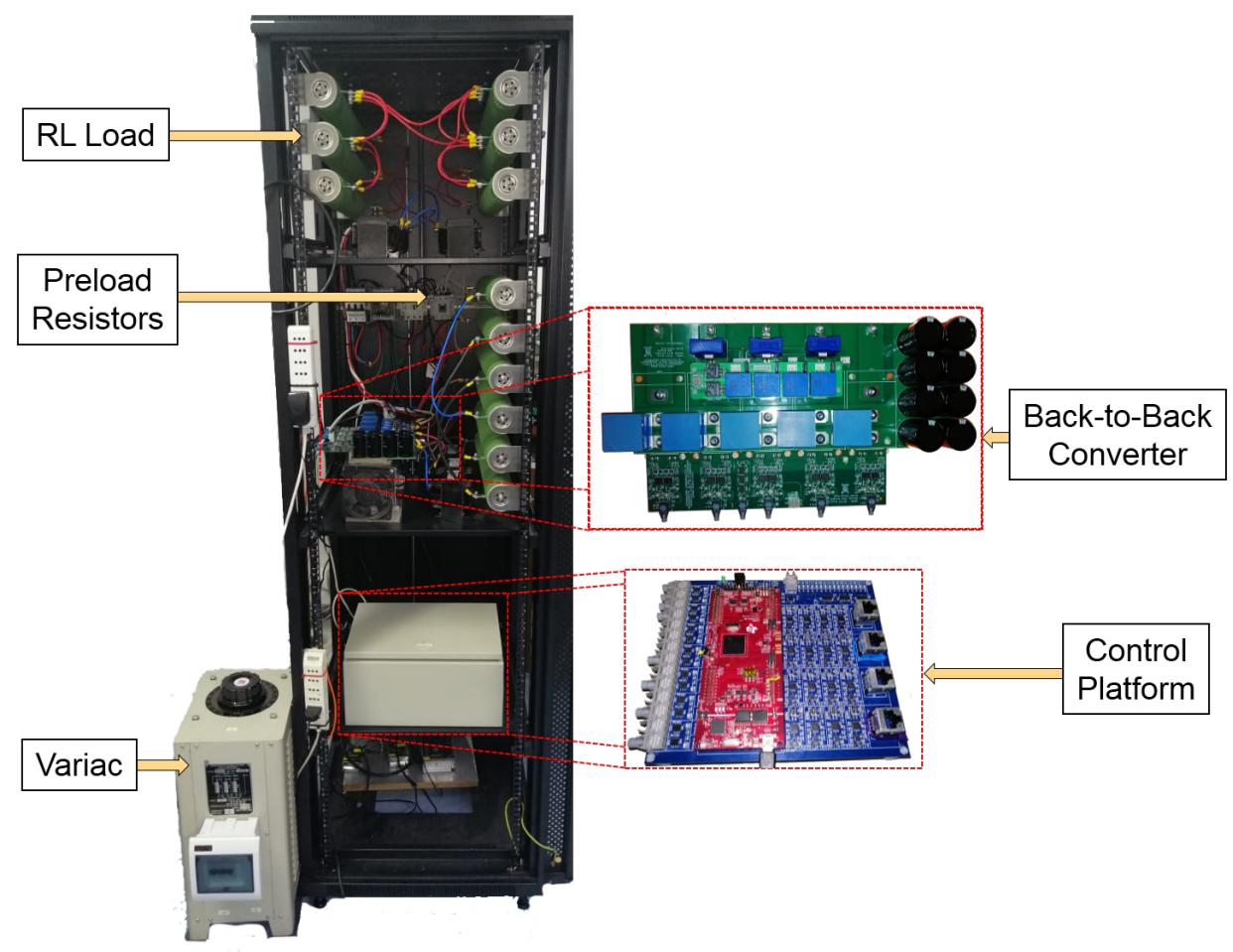

Figure 9. Experimental system implementation.

\section{Experimental Results}

In this section, four tests are described to corroborate the proper performance of the proposed RTCP as RCP controller. In the first test, the RTCP is configured to regulate the AC-DC converter as a controlled rectifier. The second test is related to the regulation of the DC-DC converter. In the third test, the current control is shown on the AC side when the converter operates at nominal power. Finally, the last test shows the operation of the hardware protections under an over-voltage scenario. 


\subsection{Test 1: Rectifier Operation}

In this test, the control of the AC-DC controlled rectifier is presented. The control algorithm displayed in Figure 8 is used. The AC-DC converter regulates the DC link voltage through the manipulation of the AC currents using a $d q$ frame control structure.

Results for step-changes in the DC link reference are presented in Figure 10. It is important to mention that both variables, DC link voltage and its references, are saved in the RTCP. Then, using RTCP-computer USB communication, those variables can be accessed and plotted.

During the first 8 seconds of this test, the voltage does not follow the reference since the control loops are not activated. In $t=8 \mathrm{~s}$, the control is enabled using the RTCP USB communication. During the rest of the test, the DC-link reference is increased until it reaches $130 \mathrm{~V}$. The converter can track the desired value regardless of the changes in the reference.

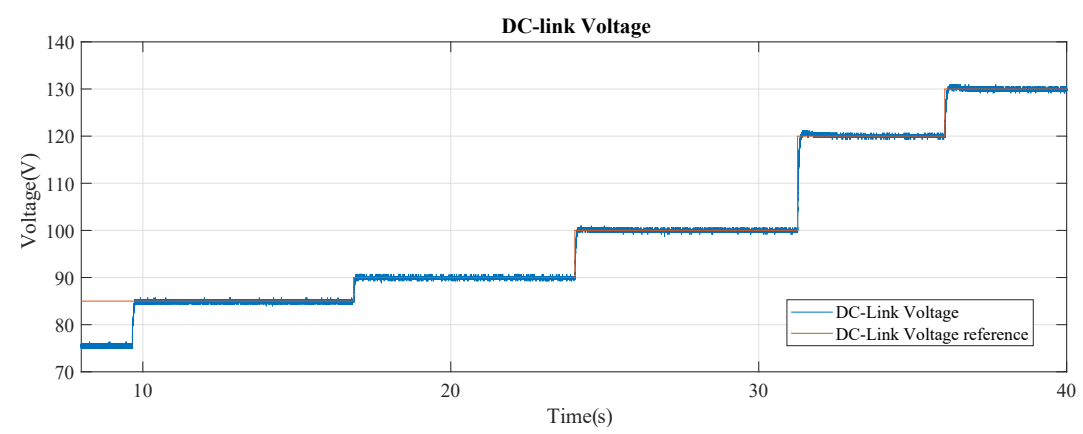

Figure 10. Variable DC link voltage reference test.

In this test, the RTCP imposes unity power factor operation. The results presented in Figure 11 shows a phase-to-neutral voltage (yellow), its respective phase current (pink), and the current in the load (green). It is verified that the converter is operating with unitary power factor since the voltage and AC current are in phase.

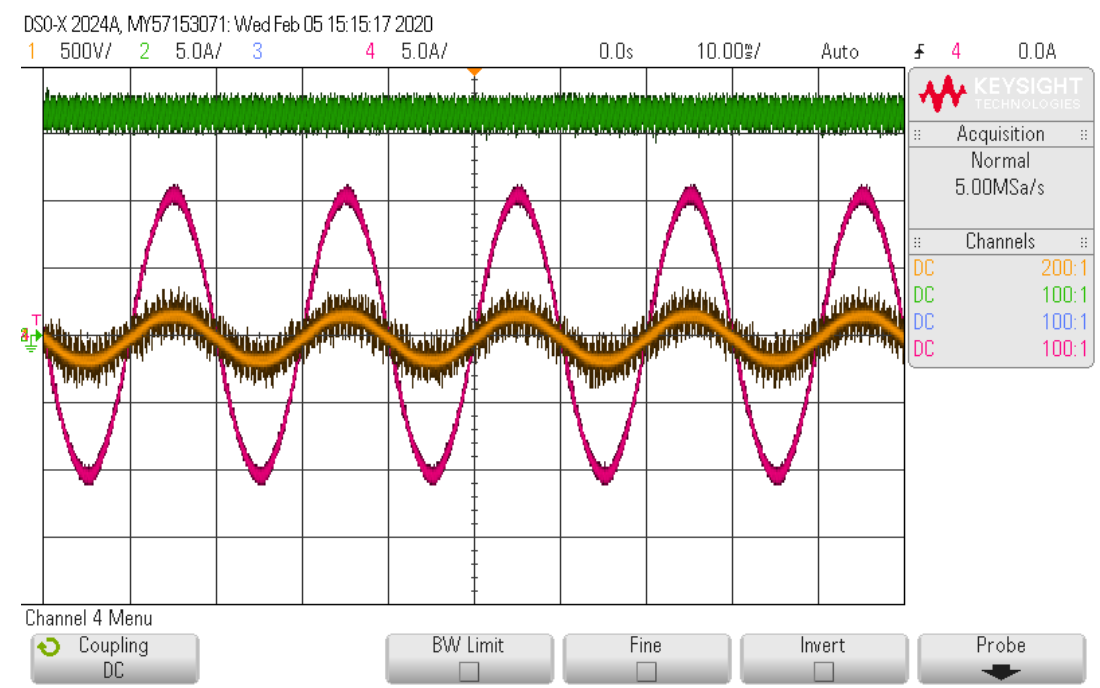

Figure 11. Steady-state operation.

\subsection{Test 2: DC Current Control}

In this case, a variable DC current reference is imposed to the DC-DC converter. As shown in Figure 8, a PI controller is programmed in the RTCP to regulate the DC current. During all the tests, proper tracking of the DC current is achieved as presented in Figure 12. 


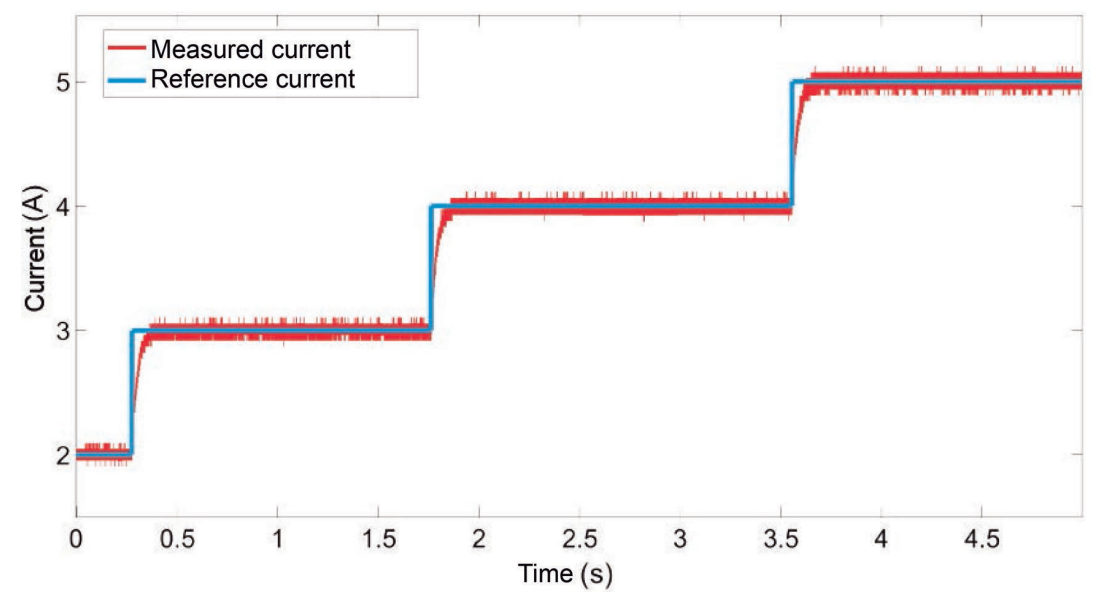

Figure 12. Variable DC current reference test.

\subsection{Test 3: Full Power Testl}

In this test, the RTCP is configured to operate the power converter at its nominal power. Then, the AC-DC back to back converter is operated to transfer $20 \mathrm{~kW}$ from the AC grid into the DC grid. The AC grid voltage is $380 \mathrm{~V}$ and the DC link voltage is set to $200 \mathrm{~V}$.

The direct current is set to $45 \mathrm{~A}$ (peak current), as shown in Figure 13a. The quadrature current is regulated to 0 (see Figure 13b). In both cases, the AC currents follow its references and low ripple is observed in the $d q$ currents. The AC waveforms of the AC currents are presented in Figure 13c. Finally, the DC current is set to 96 A, as shown in Figure 13d.

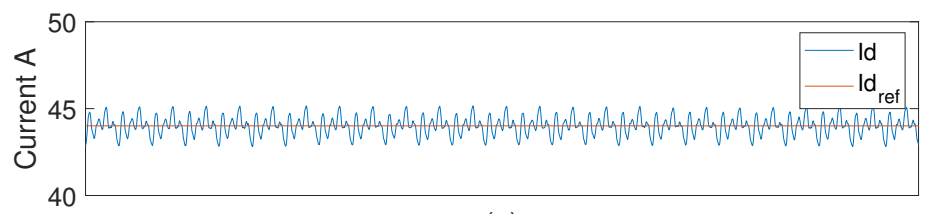

(a)

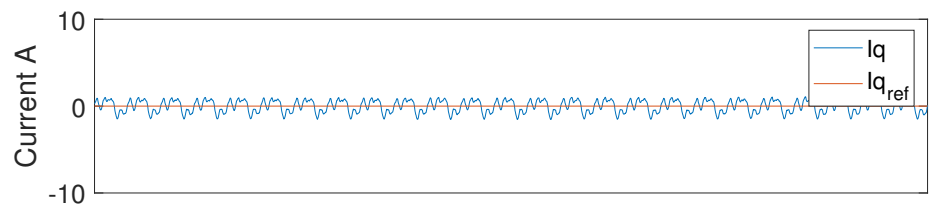

(b)

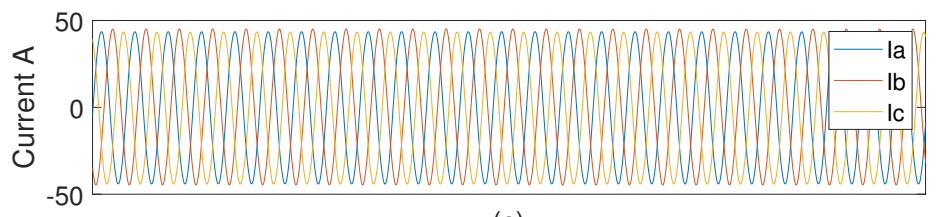

(c)

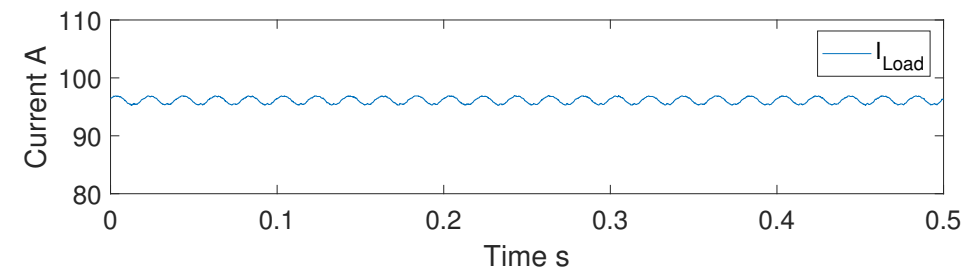

(d)

Figure 13. Experimental Results. (a) AC d-axis current. (b) AC q-axis current. (c) AC abc currents. (d) DC load current. 


\subsection{Test 4: Over-Voltage Protection}

The protection must trip and shut down the converter when any of the voltages or currents are higher than the safety threshold to avoid any potential damage in the converter.

In this case, the voltage safety threshold is set to $150 \mathrm{~V}$, and it is intentionally activated. At the beginning of the test, the DC link voltage is regulated at $100 \mathrm{~V}$, as shown in Figure 14, and the AC currents are controlled with a peak value of approximately $10 \mathrm{~A}$. After that, the DC link voltage is increased to reach its threshold. The hardware protection is activated, and then all converter switches are turned off, and the DC link capacitors begin to discharge.

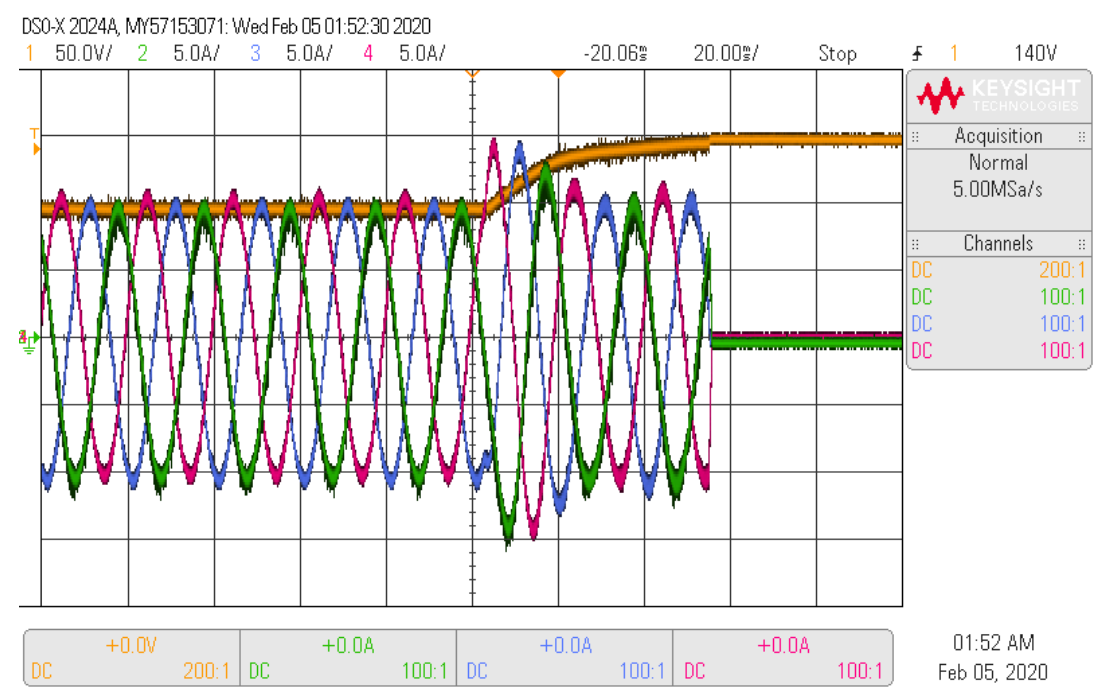

Figure 14. Over-voltage protection.

\section{Conclusions}

The design and implementation of a new RTCP for power electronic applications have been presented in this paper. The proposed RTCP is composed of the Launchpad TMS320F28379D and an expansion board to provide analogue measurements, switching signals and hardware protections. The expansion board is equipped with optical fibre drivers for 14 PWM signals and an AD conditioning interface for up to 16 analogue signals. Additionally, each AD channel is equipped with hardware protections to prevent any potential damage in the power stage.

If compared to all the current off-the-shelf solutions on the market, the proposed RTCP offers is a cheaper solution that offers a good trade-off among cost and capabilities, targeting at the segment in between expensive off-the-shelf control platforms and low-cost controllers. The RTCP features easy-to-use and straightforward programming, which is very useful for RCP applications.

Due to its capabilities, the proposed RTCP can be used as RCP in a wide range of teaching and research applications. For instance, it is expected to use it to control interlinking converters in AC-DC microgrid applications, interconnection of renewable energy generation units, and variable-speed drive for electrical machines.

Author Contributions: J.A., D.C. and M.D. worked on the RTCP design and implementation. M.U. helped to write the paper and to implement control strategies on the RTCP. R.C., F.R. and J.C.T. Travieso provided supervision on all the stages of this research work. All authors have read and agreed to the published version of the manuscript.

Funding: This work was funded by the Agencia Nacional de Investigación y Desarrollo (ANID) of Chile, under projects Fondecyt 11191163, Fondecyt 1180879, and Fondef ID19I10370.

Conflicts of Interest: The authors declare no conflicts of interest. 


\section{References}

1. Rashid, M.H. Power electronics-Challenges and trends. In Proceedings of the 2017 International Conference on Innovations in Electrical Engineering and Computational Technologies (ICIEECT), Karachi, Pakistan, 5-7 April 2017. doi:10.1109/icieect.2017.7916589. [CrossRef]

2. Suntio, T.; Messo, T. Power electronics in renewable energy systems. Energies 2019, 12, 1852. doi:10.3390/en12101852. [CrossRef]

3. Revol, B.; Azzopardi, S.; Youssef, T.; Teu, J.S.N.; Gautier, C.; Khazaka, R.; Roggia, S. Overview and new trends in technology bricks for reliability enhancement in future wide band gap power converters for More Electrical Aircraft (MEA) and More Electrical Propulsion (MEP) systems. In Proceedings of the IECON 2019-45th Annual Conference of the IEEE Industrial Electronics Society, Lisbon, Portugal, 14-17 October 2019; pp. 7128-7134. doi:10.1109/iecon.2019.8927816. [CrossRef]

4. Zhong, Q.; Matthews, C.; Nguyen, P.; Clarke, S. Low-cost Rapid Control Prototyping paradigm. In Proceedings of the UKACC International Conference on Control 2010, Coventry, UK, 7-10 September 2010; pp. 1-5. doi:10.1049/ic.2010.0463. [CrossRef]

5. Lu, J.; Guo, Y.Q.; Wang, H.Q. Rapid prototyping real-time simulation platform for digital electronic engine control. In Proceedings of the 2008 2nd International Symposium on Systems and Control in Aerospace and Astronautics, ISSCAA 2008, Shenzhen, China, 10-12 December 2008. doi:10.1109/ISSCAA.2008.4776230. [CrossRef]

6. Power Electronics and Electric Drive Technology—dSPACE. Available online: https://www.dspace.com/ en/pub/home/applicationfields/stories/electricaldrive.cfm (accessed on 5 March 2020).

7. Real-Time Simulation I OPAL-RT. Available online: https:/ / www.opal-rt.com/ (accessed on 5 March 2020).

8. Herrera, L.; Li, C.; Yao, X.; Wang, J. FPGA-Based Detailed Real-Time Simulation of Power Converters and Electric Machines for EV HIL Applications. IEEE Trans. Ind. Appl. 2015, 51, 1702-1712. doi:10.1109/TIA.2014.2350074. [CrossRef]

9. RT Box I Plexim. Available online: https://www.plexim.com/products/rt_box (accessed on 3 March 2020).

10. Control Products-Imperix. Available online: https://imperix.ch/products/control (accessed on 3 March 2020).

11. About Us।PED-Board. Available online: http://www.ped-board.com/about-us/ (accessed on 3 March 2020).

12. HIL Hardware / Typhoon HIL. Available online: https://www.typhoon-hil.com/hil-hardware/ (accessed on 4 March 2020).

13. Home-rtds-Technologies. Available online: https://www.rtds.com/ (accessed on 4 March 2020).

14. Galassini, A.; Lo Calzo, G.; Formentini, A.; Gerada, C.; Zanchetta, P.; Costabeber, A. UCube: Control platform for power electronics. In Proceedings of the 2017 IEEE Workshop on Electrical Machines Design, Control and Diagnosis, WEMDCD 2017, Nottingham, UK, 20-21 April 2017; pp. $216-221$. doi:10.1109/WEMDCD.2017.7947749. [CrossRef]

15. Wendel, S.; Geiger, A.; Liegmann, E.; Arancibia, D.; Duren, E.; Kreppel, T.; Rojas, F.; Popp-Nowak, F.; Diaz, M.; Dietz, A.; et al. UltraZohm-A powerful real-time computation platform for MPC and multi-level inverters. In Proceedings of the PRECEDE 2019: 2019 IEEE International Symposium on Predictive Control of Electrical Drives and Power Electronics, Quanzhou, China, 31 May-2 June 2019. doi:10.1109/PRECEDE.2019.8753306. [CrossRef]

16. Wang, Y.; Nguyen, T.L.; Xu, Y.; Li, Z.; Tran, Q.; Caire, R. Cyber-Physical Design and Implementation of Distributed Event-Triggered Secondary Control in Islanded Microgrids. IEEE Trans. Ind. Appl. 2019, 55, 5631-5642. doi:10.1109/TIA.2019.2936179. [CrossRef]

17. Wang, Y.; Syed, M.H.; Guillo-Sansano, E.; Xu, Y.; Burt, G.M. Inverter-Based Voltage Control of Distribution Networks: A Three-Level Coordinated Method and Power Hardware-in-the-Loop Validation. IEEE Trans. Sustain. Energy 2019. doi:10.1109/TSTE.2019.2957010. [CrossRef]

18. Lu, B.; Wu, X.; Monti, A. Implementation of a low-cost real-time virtue test bed for hardware-in-the-loop testing. In Proceedings of the 31st Annual Conference of IEEE Industrial Electronics Society, IECON 2005, Raleigh, NC, USA, 6-10 November 2005. doi:10.1109/IECON.2005.1568910. [CrossRef] 
19. Lu, B.; Wu, X.; Figueroa, H.; Monti, A. A Low-Cost Real-Time Hardware-in-the-Loop Testing Approach of Power Electronics Controls. IEEE Trans. Ind. Electron. 2007, 54, 919-931. doi:10.1109/TIE.2007.892253. [CrossRef]

20. Bastos, R.F.; Fuzato, G.H.; Aguiar, C.R.; Neves, R.V.A.; Machado, R.Q. Model, design and implementation of a low-cost HIL for power converter and microgrid emulation using DSP. IET Power Electron. 2019, 12, 3833-3841. doi:10.1049/iet-pel.2019.0302. [CrossRef]

21. Jacobs, I.; Miller, S.E. Communications: Optical transmission of voice and data: Bandwidth and noise immunity are up; size, weight, and costs are down. IEEE Spectrum 1977, 14, 33-41. doi:10.1109/MSPEC.1977.6369325. [CrossRef]

22. Zhang, X.; Li, H.; Brothers, J.A.; Fu, L.; Perales, M.; Wu, J.; Wang, J. A Gate Drive With Power Over Fiber-Based Isolated Power Supply and Comprehensive Protection Functions for 15-kV SiC MOSFET. IEEE J. Emerg. Sel. Top. Power Electron. 2016, 4, 946-955. doi:10.1109/JESTPE.2016.2586107. [CrossRef]

23. Modeling Basics-MATLAB \& Simulink-MathWorks. Available online: https://es.mathworks.com/help/ supportpkg/texasinstrumentsc2000/modeling-basics.html?category=modeling-basics\&s_tid=CRUX_gn_ documentation_modeling-basics (accessed on 3 March 2020).

24. Pan, L.; Zhang, C. An integrated multifunctional bidirectional AC/DC and DC/DC converter for electric vehicles applications. Energies 2016, 9, 493. doi:10.3390/en9070493. [CrossRef]

25. Fitri, I.R.; Kim, J.S.; Song, H. A robust suboptimal current control of an interlink converter for a hybrid AC/DC microgrid. Energies 2018, 11, 1382. doi:10.3390/en11061382. [CrossRef]

26. Díaz, M.; Cárdenas-Dobson, R. Dual current control strategy to fulfill LVRT requirements in WECS. COMPEL Int. J. Comput. Math. Electr. Electron. Eng. 2014, 33, 1665-1677. doi:10.1108/COMPEL-09-2013-0305. [CrossRef]

27. Blaabjerg, F.; Teodorescu, R.; Liserre, M.; Timbus, A.V. Overview of control and grid synchronization for distributed power generation systems. IEEE Trans. Ind. Electron. 2006, 53, 1398-1409. doi:10.1109/TIE.2006.881997. [CrossRef]

(C) 2020 by the authors. Licensee MDPI, Basel, Switzerland. This article is an open access article distributed under the terms and conditions of the Creative Commons Attribution (CC BY) license (http://creativecommons.org/licenses/by/4.0/). 